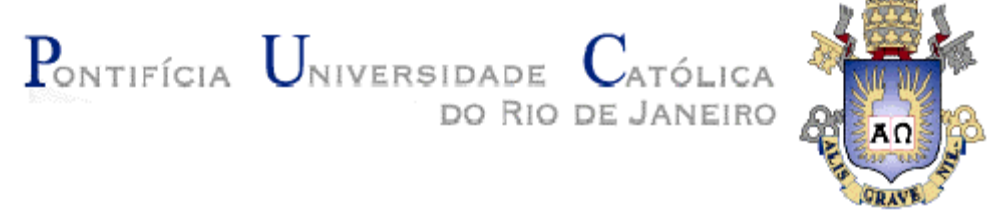

Edson Diniz Nóbrega Junior

\title{
O Programa Criança Petrobras na Maré em oito escolas públicas do maior conjunto de favelas do Brasil
}

Dissertação apresentada como requisito parcial para obtenção do grau de Mestre pelo Programa de Pós-Graduação em Educação do Departamento de Educação da PUC-Rio.

Orientador: Profa ${ }^{a}$ Alicia Maria Catalano Bonamino 


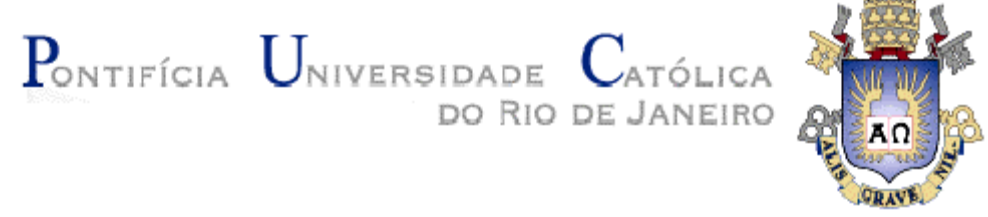

Edson Diniz Nóbrega Junior

O Programa Criança Petrobras na Maré em oito escolas
públicas do maior conjunto de favelas do Brasil

Dissertação apresentada como requisito parcial para obtenção do grau de Mestre pelo Programa de Pós-Graduação em Educação do Departamento de Educação do Centro de Teologia e Ciências Humanas da PUC-Rio. Aprovada pela Comissão Examinadora abaixo assinada.

\author{
Profa. Alicia Maria Catalano Bonamino \\ Orientadora \\ Departamento de Educação - PUC-Rio \\ Prof ${ }^{a}$ Zaia Brandão \\ Departamento de Educação - PUC-Rio
}

Prof. Jorge Luiz Barbosa

UFF

Prof. Paulo Fernando C. de Andrade Coordenador Setorial do Centro de

Teologia e Ciências Humanas

Rio de Janeiro, 13 de julho de 2007 
Todos os direitos reservados. É proibida a reprodução total ou parcial do trabalho sem autorização da universidade, da autora e do orientador.

\section{Edson Diniz Nóbrega Junior}

Edson Diniz Nóbrega Junior grudou-se em História pela Universidade do Estado do Rio de Janeiro (UERJ) em 1999. Em 2007 concluiu o Curso de Mestrado em Educação na Puc-Rio apresentando a dissertação: "O Programa Criança Petrobras na Maré em oito escolas públicas do maior conjunto de favelas do Brasil". Desde 1994, exerce a função de professor de História da rede particular da cidade do Rio de Janeiro. Entre 2003 e 2004 foi professor da rede municipal de Nilópolis. É professor da rede estadual do Rio de Janeiro desde 2007. Dirigiu o Centro de Estudos e Ações Solidárias da Maré (CEASM) entre 2001 e 2007. Atualmente é diretor da Associação Redes de Desenvolvimento da Maré (Redes da Maré).

Ficha Catalográfica

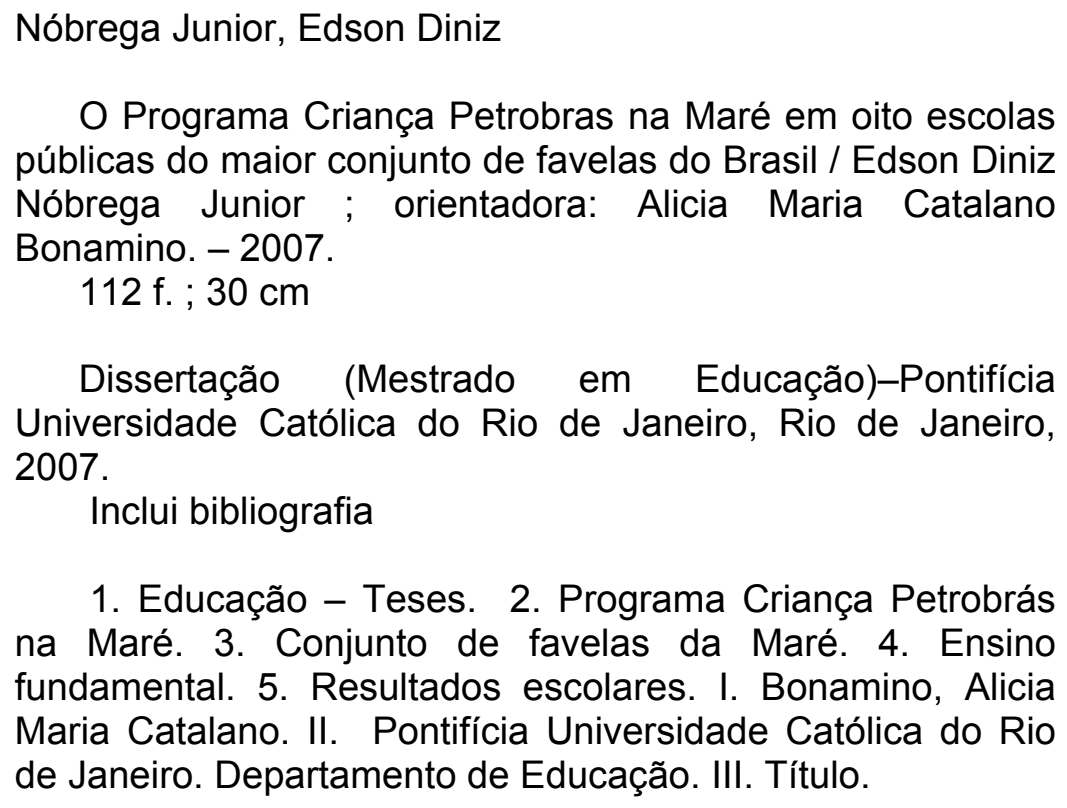

O Programa Criança Petrobras na Maré em oito escolas públicas do maior conjunto de favelas do Brasil / Edson Diniz Nóbrega Junior ; orientadora: Alicia Maria Catalano Bonamino. -2007.

112 f. ; $30 \mathrm{~cm}$

Dissertação (Mestrado em Educação)-Pontifícia Universidade Católica do Rio de Janeiro, Rio de Janeiro, 2007.

Inclui bibliografia

1. Educação - Teses. 2. Programa Criança Petrobrás na Maré. 3. Conjunto de favelas da Maré. 4. Ensino fundamental. 5. Resultados escolares. I. Bonamino, Alicia Maria Catalano. II. Pontifícia Universidade Católica do Rio de Janeiro. Departamento de Educação. III. Título.

CDD: 370 
Dedico este trabalho à minha companheira de todas as horas e grande amor desta vida, Janete Félix. 


\section{Agradecimentos}

À minha Orientadora Professora Alicia Bonamino pela orientação segura, estimulante, paciente, competente e amiga. Muito obrigado.

Aos professores e professoras do Programa de Pós-Graduação em Educação do Departamento de Educação da PUC-Rio com quem aprendi muito e guardo excelentes lembranças e ensinamentos.

Aos colegas de turma que me acompanharam nessa jornada, especialmente ao "núcleo duro": Zé Café, Ceará, Rita, Roberta, Lúcia, Indira, Fernando, Fernanda, Gilda, Tinhinha e Verena.

Aos amigos Elisângela Bernardo, Juliana Santino, Carla Santino, Cláudia Santos e Dálcio. Pela ajuda inestimável.

Aos queridos amigos Eliana e Jaílson. Muito obrigado pelo incentivo, pelo apoio e pela sincera amizade.

A meus amigos da Rua Principal, na Maré, com quem aprendo o valor da amizade, do carinho e do respeito a cada dia.

Aos Amigos(as) do Observatório de Favelas com quem tenho aprendido tanto nesses últimos tempos.

Aos Amigos(as) do CEASM com quem tenho compartilhado dores e alegrias nesses últimos dez anos.

À Coordenação e equipe do Programa Criança Petrobras na Maré.

A meus queridos sobrinhos, Juliana, Vitor, Vinícius. Agradeço por sua alegria contagiante e por me permitir sonhar com um mundo melhor.

Aos meus irmãos Underson e Nívea. A minha cunhada, Roseli. Obrigado pelo apoio e o carinho.

Aos meus pais, Edson e Nina. Pessoas que sempre batalharam muito nesta vida com uma dignidade absoluta e que me ensinaram tudo que sei e que sou hoje. Muito obrigado.

A Banca Examinadora pelo aceite e pela disponibilidade.

Ao CNPq e à PUC-Rio, pelos auxílios concedidos, sem os quais este trabalho não poderia ter sido realizado. 


\section{Resumo}

Nóbrega Júnior, Edson Diniz; Bonamino, Alicia Maria Catalano. O Programa Criança Petrobras na Maré em oito escolas públicas do maior conjunto de favelas do Brasil. Rio de Janeiro, 2007, 112 p. Dissertação de Mestrado - Departamento de Educação, Pontifícia Universidade Católica do Rio de Janeiro.

Em 1999, a empresa estatal Petrobras e o CEASM (Centro de Estudos e Ações Solidárias da Maré) instituição comunitária localizada na Maré, o maior conjunto de favelas do país, estabeleceram uma parceria que visava auxiliar algumas escolas públicas locais a desempenhar melhor o seu papel. Dessa parceria nasceu o Programa Criança Petrobras na Maré que, junto com a idéia de ajudar a melhorar as escolas tinha, também, entre seus objetivos a melhoria do desempenho escolar dos estudantes. Isso deveria ocorrer por meio do oferecimento de "oficinas" pedagógicas e culturais complementares à grade curricular regular. Com essa ação, esperava-se que os alunos atendidos pudessem ampliar seu capital cultural e seu capital escolar e, conseqüentemente, melhorar seu desempenho. Atualmente, o Projeto atende a metade das escolas públicas municipais de Ensino Fundamental existentes na Maré, o que significa o atendimento a oito escolas. Diante disso, a interrogação principal que guia este estudo refere-se a possíveis relações entre o Programa Criança Petrobras na Maré e o desempenho escolar dos estudantes das oito escolas em que o mesmo se faz presente. Para tentar responder a esta questão, analisamos um conjunto de indicadores escolares, incluindo os resultados dos estudantes dessas escolas na Prova Brasil de 2005 e estabelecemos comparações com as oito escolas públicas não atendidas pelo Programa. Entre os principais achados da pesquisa, está a melhoria das notas obtidas pelos alunos de turmas atendidas pelo Programa em avaliações pedagógicas dos professores.

\section{Palavras-chave:}

Programa Criança Petrobras na Maré, Conjunto de favelas da Maré, Ensino Fundamental, Resultados Escolares. 


\section{Abstract}

Nóbrega Júnior, Edson Diniz; Bonamino, Alicia Maria Catalano (Advisor). Le Programme Enfant Petrobras, à la Maré, chez huit écoles publiques situés au plus grand ensemble de bidonvilles du Brésil, et sa relation au progrè des élèves. Rio de Janeiro, 2007, 112 p. MSc. Dissertation Departamento de Educação, Pontifícia Universidade Católica do Rio de Janeiro.

En 1999, l'entreprise Petrobras et le Centre d'Études Solidaires de la Maré (CEASM), instituition localisé dans la Maré, ont etabli une alliance que visais aider les écoles bubliques de la localilé, à accomplir mielleur leur objectve. On peut dire, que de cette alliance est né, le Programme Entfant Petrbrasavec, l'ideé de potencialiser la perfomance scolaire des élèves et, entre autres objectives, améliorer les écoles. Afin de bien concrétizer ce projet, la médiation devrait se donner par le développement des "officines" pédagogique et culturelles, complémentaires au curriculum régulière. Dans cette perspective, on espérait, rendre possible l'ampliation du capital culturel et scolaire des élèves, et en conséquence elever leurs performances. Actuellement, la moitié des écoles publique, municipal, d'enseignement fondamental existant à la Maré sont bneficié par le projet. Ça signfie huit écoles. Devant le cadre designé, l'interogation principal, de ce travail, pose en question les possibles relations entre le programme, déjà mentionner, et la performance scolaire des élèves. Pour essayer de repondre cette question, nous avons analiser un ensemble de données, des indicateurs scolaires, le resultat de la performance de ces élèves à la Preuve Brésil de 2005 et, ensuite, nous avons établi une comparaisons avec les autres, huit, écoles non bénéficié par le programme. Entre, les principaux constatations de la recherche, on peut détacher l'élévation de performance des élèves aux examens pedagogiques faites par les instituteurs.

\section{Key-words:}

Le Programme Enfant Petrobras, ensemble de bidonvilles du Brésil, d'enseignement fondamental, resultat de la performance. 


\section{Sumário}

1. Introdução

2. O Lugar do Pobre na cidade: dos Cortiços às favelas ............................. 18

2.1. O Cortiço: o lugar das "classes perigosas" .......................................... 18

2.2. A favela: o lugar dos pobres na cidade .............................................. 24

2.3. $\mathrm{O}$ crescimento das favelas e sua invisibilidade ..................................... 28

2.4. A constituição da Maré ...................................................................... 35

2.5. A favela: os discursos estruturantes ................................................. 44

3. O CEASM e o Censo da Maré ......................................................... 51

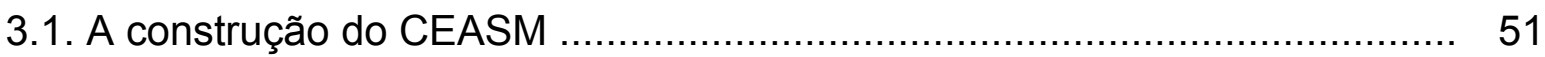

3.2. O Censo Maré e as características da Maré .................................... 55

4. O Programa Criança Petrobrás na Maré ..................................................... 65

4.1. A antinomia entre a lógica socializadora da escola e a lógica socializadora das famílias dos espaços populares

4.2. A metodologia do Programa Criança Petrobrás na Maré ......................... 75

4.3. Os efeitos do Programa Criança Petrobrás na Maré nas turmas atendidas 81

4.4. A relação entre o Programa Criança Petrobrás e os resultados macroescolares dos estudantes

5. Considerações Finais 101

6. Referências Bibliográficas 


\section{Lista de Tabelas}

Tabela 1 - Crescimento da População residente em favelas no município do Rio de Janeiro

Tabela 2 - Circulação dos moradores da Maré por outras comunidades

Tabela 3 - Circulação dos moradores da Maré por bairros da zona sul e Barra da Tijuca

Tabela 4 - Percentual de moradores que faria um curso em outra comunidade 16

Tabela 5 - Renda dos moradores segundo sua comunidade 19

Tabela 6 - Conceitos adotados em 2002 pela SME e sua conversão em nota ... 22 Tabela 7 - Conceitos adotados entre 2003 e 2005 pela SME e sua conversão em nota

\section{Lista de Quadros}

Quadro 1 - Remoções realizadas no Estado da Guanabara no período de 1962-1974

Quadro 2 - Escolas da Maré por comunidades e ano de fundação

Quadro 3 - Atendimentos realizados pelas oficinas e projetos do Programa

Criança Petrobrás na Maré em 2005 16

Quadro 4 - Oficinas do Programa Criança Petrobras na Maré 16

Quadro 5 - Projetos do Programa Criança Petrobrás na Maré 19

Quadro 6-Média em proficiência em Leitura - $4^{\text {a }}$ série do E. F - Língua Portuguesa, Brasil, estado do RJ e município do Rio de Janeiro na Prova Brasil de 2005 


\section{Lista de Gráficos}

Gráfico 1 - Médias das notas obtidas em Língua Portuguesa pelas turmas atendidas pelo Programa em 2002

Gráfico 2 - Médias das notas obtidas em Língua Portuguesa pelas turmas não atendidas pelo Programa em 2002

Gráfico 3 - Médias das notas obtidas em Língua Portuguesa pelas turmas atendidas pelo Programa em 2003

Gráfico 4 - Médias das notas obtidas em Língua Portuguesa pelas turmas não atendidas pelo Programa em 2003

Gráfico 5 - Médias das notas obtidas em Língua Portuguesa pelas turmas atendidas pelo Programa em 2004

Gráfico 6 - Médias das notas obtidas em Língua Portuguesa pelas turmas não atendidas pelo Programa em 2004

Gráfico 7 - Médias das notas obtidas em Língua Portuguesa pelas turmas atendidas pelo Programa em 2005

Gráfico 8 - Médias das notas obtidas em Língua Portuguesa pelas turmas não atendidas pelo Programa em 2005

Gráfico 9 - Média em proficiência - $4^{\text {a }}$ série - Escolas da Maré em Língua Portuguesa na Prova Brasil de 2005 16

Gráfico 10 - Taxa de não-aprovação E.F. nas escolas da Maré 16

Gráfico 11 - Taxa de distorção idade-série no período de 1996 a 2005 nas escolas da Maré

Gráfico 12 - Taxas de Abandono escolar nas escolas em 2004 nas escolas da Maré 